\title{
Interactions of dopamine and dopamine hydrochloride with ethanol
}

Cuiping Zhai ${ }^{1,2}$ Fang Sun ${ }^{2}$ Ping Zhang ${ }^{2}$ Huiting Ma ${ }^{2}$ Aixin Song ${ }^{1, *}$ Jingcheng Hao ${ }^{1}$

${ }^{1}$ Key Laboratory of Colloid and Interface Chemistry, Shandong University, Ministry of Education, Jinan 250100, China

${ }^{2}$ Institute of Fine Chemical and Engineering, Henan University, Kaifeng 475004, China

\begin{abstract}
Cyclic voltammetry (CV), density functional theory (DFT) calculations, and atoms in molecules (AIM) analyses were performed to investigate the hydrogen bonding in dopamine-ethanol and dopamine hydrochloride-ethanol mixtures. CV results show that the anodic/cathodic peak potential of dopamine hydrochloride in ethanol is influenced by the hydrogen bonding formed in the mixtures. The DFT and AIM results indicate that the hydrogen atoms of $-\mathrm{NH}_{3}{ }^{+}$in dopamine hydrochloride-ethanol system are easier to interact with ethanol by hydrogen bonding than those in dopamine-ethanol system. On the contrary, the hydrogen atoms on phenolic hydroxyl groups can form stronger hydrogen bonding with ethanol in dopamine-ethanol system than in dopamine hydrochloride-ethanol system.
\end{abstract}

Keywords: Dopamine; Dopamine hydrochloride; Hydrogen bonding; Ethanol

\footnotetext{
* Corresponding author, E-mail: songaixin@sdu.edu.cn
} 


\section{Introduction}

Dopamine (DA) is an important neurotransmitter and plays critical roles in many physiological processes. DA can control our emotions, being closely related to drug addiction, such as nicotine and ethanol. Ethanol is one of the most widely used recreational drugs, which can influence the behaviors of many systems participated by DA. A number of studies demonstrated that ethanol promoted an increasing dopamine turnover and release in various brain areas [1-4]. In addition, ethanol can also alter the in vivo DA uptake. Furthermore, ethanol abuse caused a worldwide serious health and social problems, for which the dopamine system has been evaluated as a potential treatment target for alcoholism [5].

The effect of ethanol on DA systems relates to the interactions between ethanol and DA, which can directly affect the distribution, storage, transport and metabolism of ethanol in vivo. Many reports were found to devote the study on dopamine systems with ethanol from a biological or medical point, with the results usually being confined to the effect of ethanol on dopamine systems, dopamine receptors, dopamine antibodies, and so on [6-10]. However, up to now, no reports were found to focus the interaction mechanism and nature on dopamine with ethanol from a chemical molecular interaction view.

In this work, we studied the interactions between DA and ethanol in molecular level by cyclic voltammetry (CV), density functional theory (DFT) calculations and atoms in molecules (AIM) analyses, focusing on the active sites and interaction nature of the molecules. It is expected that the results of the present work can not only deepen the understanding of the role of ethanol in dopamine systems, but can also be helpful for further study on the mechanism of ethanol addiction, thus can providing theoretical basis for new and more effective treatment strategies. 


\section{Experimental Methods and Calculations}

Dopamine hydrochloride (BR) was obtained from Sigma. Ethanol (SP) was purchased from Aladdin. The solvent, ethanol, was degassed by bubbling highly pure nitrogen for 15 min before the preparation of samples.

Cyclic voltammetry was performed on a CHI660E electrochemical workstation (Shanghai Chenhua Co., China). Electrochemical tests were carried out using a conventional three-electrode system: a glassy carbon as the working electrode, a platinum wire as the counter electrode and a saturation calomel electrode (SCE) as the reference electrode. GCE was polished on alumina slurry $(0.05 \mu \mathrm{m})$, rinsed with distilled water, cleaned in an ultrasonic aqueous bath, and then rinsed with distilled water, electrochemically cleaned by cycling the potential between $-0.2 \mathrm{~V}$ and $0.6 \mathrm{~V}$ (vs.SCE) at a scan rate of $50 \mathrm{mV} \cdot \mathrm{s}^{-1}$ in mixtures of $5 \mathrm{mmol} \cdot \mathrm{L}^{-1}$ $\mathrm{K}_{3}\left[\mathrm{Fe}(\mathrm{CN})_{6}\right] / \mathrm{K}_{4}\left[\mathrm{Fe}(\mathrm{CN})_{6}\right]$ and $0.1 \mathrm{~mol} \cdot \mathrm{L}^{-1} \mathrm{KCl}$ solution until a peak separation $\left(\Delta E_{\mathrm{p}}<\right.$ $80 \mathrm{mV}$ ) was obtained. All experiments were operated at room temperature.

DFT calculations were performed at the $\omega \mathrm{B} 97 \mathrm{XD} / 6-311++\mathrm{G}(\mathrm{d}, \mathrm{p})$ level using the Gaussian 09 program [11]. All complexes were constructed from the most stable optimized geometrical structures of monomers, and fully optimized in gas phase at the above level. The calculations were repeated in ethanol using the SMD model. The fact that stationary points were minima was confirmed by the absence of imaginary frequencies. The interaction energy $(\Delta E)$ was evaluated according to the following equation:

$$
E=E(\mathrm{AB})-E(\mathrm{~A} 0)-E(\mathrm{~B} 0)+E(\mathrm{BSSE})
$$

where $E(\mathrm{AB}), E(\mathrm{~A} 0)$ and $E(\mathrm{~B} 0)$ are the energy of the complex, monomer $\mathrm{A}$ and monomer $\mathrm{B}$, respectively. $E(\mathrm{BSSE})$ is the basis set superposition error (BSSE) estimated using the counterpoise method [12]. AIM analyses were performed using 
AIM2000 program [13].

\section{Results and Discussion}

Cyclic voltammetry is a simple and useful method to investigate the intermolecular interactions. The cyclic voltammograms of protonated dopamine, dopamine hydrochloride (DH) in ethanol at different concentrations were shown in Fig. 1. Two peaks were found: the oxidation peak (wave 2), being produced by the oxidation process from dopamine to dopaminequinone; the cathodic peak (wave 1), corresponding to the reverse reaction [14]. The peak currents can also be found gradually increase with the concentration of $\mathrm{DH}$, for which the oxidation peak current is higher than that of the reduction peak current, suggesting a irreversible electron transfer process $[15,16]$.

Fig. 1 also shows that, with DH concentration increasing, the anodic peak potential exhibits a positive shift, while the cathodic peak potential exhibits a negative shift, indicating the more difficult oxidation process and the easier reduction process. Combined with our previous studies $[17,18]$, the reason can be ascribed to the existence of hydrogen bonding between the hydrogen atoms of phenolic hydroxyls on DH molecules and the hydroxyl groups on ethanol molecules. Therefore, the phenolic hydroxyl groups are protected to be difficult to donate protons, which results in a more difficult oxidation process of DH and the increasing anodic peak potential.

Quantum chemical calculations are effective for theoretical studies on hydrogen bonding. In order to confirm the hydrogen bonding in DH-ethanol system, the optimized geometries of $\mathrm{DH}^{+}$and ethanol and the different interaction sites of $\mathrm{DH}^{+}$ with ethanol were studied using DFT calculations in gas phase and in ethanol. The most stable conformation of $\mathrm{DH}^{+}$-ethanol complexes in gas phase was obtained and shown in Figs. 2 and 3. The structural parameters of hydrogen bonding are listed in 
Table 1, in which one can find that the $\mathrm{H} \cdots \mathrm{O}$ distances are shorter than $2.7 \AA$ (the sum of the van der Waals radii of $\mathrm{H}$ and $\mathrm{O}$ atoms: $\mathrm{H}, 1.20 \AA$; $\mathrm{O}, 1.50 \AA$ ), and the $\mathrm{Y}-\mathrm{H} \cdots \mathrm{O}$ angles are larger than $90^{\circ}[19,20]$.

From Fig. 3 and Table 1, one can see that the hydrogen and oxygen atoms on the phenolic hydroxyl groups, the hydrogen atoms on the amino group, and the hydrogen atom (H9) on the aromatic ring of $\mathrm{DH}$ molecule all can form hydrogen bonding with the hydrogen atom or oxygen atom on the hydroxyl group of ethanol. Generally, the strength and the length of the hydrogen bonding are closely related, for which the shorter distance is attributed to the stronger interaction [21,22]. The strength of hydrogen bonding between $\mathrm{DH}^{+}$and ethanol of the complexes is in the order: a5 > a7 $>$ a $6>$ a $>$ a $3>$ a $4>$ a2. Moreover, it is also observed that the interaction energies of complexes a5-a7 are lower than that of complexes a1-a4. The above results indicate that complexes a5-a7 are more stable among complexes of $\mathrm{DH}^{+}$-ethanol mixtures in gas phase.

The geometries of $\mathrm{DH}^{+}$-ethanol complexes in ethanol are similar to those in gas phase, for which the structural parameters of hydrogen bonding are also listed in Table 1. In contrast to the gas phase, the strength and angle of hydrogen bonding changed in ethanol for the same complex. Moreover, for all complexes, the interaction energies in ethanol are higher than those in gas phase. Compared with the interaction energy in ethanol, we can find that complex a6 is the more stable conformation. The results also indicate that the hydrogen atoms on $-\mathrm{NH}_{3}{ }^{+}$are easier to interact with ethanol by hydrogen bonding than that of phenolic hydroxyl groups in ethanol as well as in gas phase.

It is interesting to note that the interaction energy of complex a4 is slightly higher than complex a6 with the shortest distance, which suggests that H13 has the 
ability to form hydrogen bonding in ethanol, being in good agreement with the experimental results.

The aim of this work is to study the interaction of DA with ethanol. We choose DH to replace DA in electrochemical tests because DA could not be purchased. Fortunately, DFT calculations can study the interaction between DA and ethanol (Figs. 4 and 5 and Table 2) in gas phase and in ethanol. By comparing the calculation results of $\mathrm{DH}^{+}$-ethanol and DA-ethanol complexes, we find that the interaction types and sites in DA-ethanol mixture are similar to those in $\mathrm{DH}^{+}$-ethanol mixture, for which the interaction energy of every complex in ethanol is higher than that in gas phase. The strength and angle of hydrogen bonding are different for the same complex in two phases with the $\mathrm{H} 11 \cdots \mathrm{O} 28$ and $\mathrm{H} 13 \cdots \mathrm{O} 28$ bonds in complexes b1 and b4 having shorter distance than others. Furthermore, the energy of complexes b1 and b4 are lower than that of other complexes. The results reveal that the hydrogen atoms on phenolic hydroxyl group are easier to form hydrogen bonding than those on $-\mathrm{NH}_{2}$ groups, being different from DH-ethanol mixture.

Atoms in molecules (AIM) theory is a very useful tool in analyzing hydrogen bonding [23-25]. Topology parameters, such as the electron density $(\rho)$, the Laplacian of electron density $\left(\nabla^{2} \rho\right)$ and the total electron energy density $(H)$ at the bond critical point $(\mathrm{BCP})$ are often used to describe the hydrogen bonding strength. Here, $H$ includes the electronic potential energy density $(V)$ and the electronic kinetic energy density $(G)$. According to the criteria [26], for intermolecular hydrogen bonding, the value of $\rho$ and $\nabla^{2} \rho$ at BCP should be within the range $0.002-0.040$ a.u. and $0.024-$ 0.139 a.u., respectively. The larger $\rho$ value corresponds to the stronger hydrogen bonding [22,27]. In addition, the strong hydrogen bonding possesses a property of $\nabla$ ${ }^{2} \rho<0$ and $H<0$, and a covalent character; the medium hydrogen bonding has a 
partially covalent character with $\nabla^{2} \rho>0$ and $H<0$; for weak hydrogen bonding, $\nabla$ ${ }^{2} \rho>0$ and $H>0$, mainly being electrostatic in nature [28].

To gain more insights into the hydrogen bonding, AIM analysis have been performed to $\mathrm{DH}^{+}$-ethanol and DA-ethanol complexes. Tables 3 and 4 list the topology parameters of all $\mathrm{DH}^{+}$-ethanol complexes. The calculated results in gas phase show that the $\rho$ and $\nabla^{2} \rho$ values for hydrogen bonding of $\mathrm{O} 30-\mathrm{H} 31 \cdots \mathrm{O} 12$ $\mathrm{O} 30-\mathrm{H} 31 \cdots \mathrm{O} 10$ and $\mathrm{C} 4-\mathrm{H} 9 \cdots \mathrm{O} 30$ lie within the above mentioned range with positive $H$ values. While for other hydrogen bonding, the $\rho$ values pass the upper limit of the range with the negative $H$ values, and $\nabla^{2} \rho>0$. Therefore, other interactions could be considered as medium hydrogen bonding with partially covalent nature [20,29].

In the case of the complexes in ethanol, the $\rho$ values of $\mathrm{O} 12-\mathrm{H} 13 \cdots \mathrm{O} 30$ and $\mathrm{N} 20-\mathrm{H} 22 \cdots \mathrm{O} 30$ pass the upper limit of the range, and all the $H$ values are negative except $\mathrm{O} 30-\mathrm{H} 31 \cdots \mathrm{O} 10$. In addition, all the $\nabla^{2} \rho$ values are in the range. This suggests that all hydrogen bonding have the partially covalent property only with $\mathrm{O} 30-\mathrm{H} 31 \cdots \mathrm{O} 10$ as an exception. Moreover, except $\mathrm{O} 12-\mathrm{H} 13 \cdots \mathrm{O} 30$ in complex a4 in ethanol, all $\rho$ values of $\mathrm{N}-\mathrm{H} \cdots \mathrm{O}$ bonding are larger than those of $\mathrm{O}-\mathrm{H} \cdots \mathrm{O}$ bonding both in gas phase and ethanol, demonstrating the stronger interaction. The AIM analysis is in good agreement with the DFT results.

AIM data for DA-ethanol complexes in gas phase and ethanol are collected in Table 5 and Table 6 , respectively. The results in the two phases are very similar with

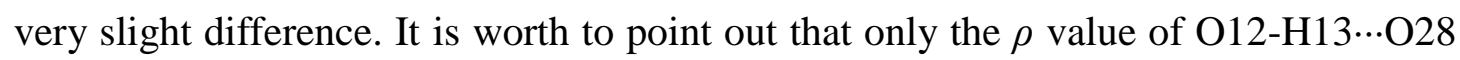
in complex b4 in ethanol exceeds the range, the $\rho$ and $\nabla^{2} \rho$ values of other complexes are all within the AIM range, showing the hydrogen bonding character in nature. As for the $H$ values, only $\mathrm{O} 10-\mathrm{H} 11 \cdots \mathrm{O} 28$ and $\mathrm{O} 12-\mathrm{H} 13 \cdots \mathrm{O} 28$ have negative values, for which the partially covalent property are presented. Moreover, all $\rho$ values of $\mathrm{O}-\mathrm{H} \cdots \mathrm{O}$ 
are larger than those of $\mathrm{N}-\mathrm{H} \cdots \mathrm{O}$ except $\mathrm{O} 28-\mathrm{H} 29 \cdots \mathrm{O} 12$ in complex b3 in gas phase, further reveals the stronger interaction of $\mathrm{O}-\mathrm{H} \cdots \mathrm{O}$ than that of $\mathrm{N}-\mathrm{H} \cdots \mathrm{O}$ in DA-ethanol mixture.

\section{Conclusions}

Ethanol has specific effect on dopamine systems. In this work, the interactions of DH and DA with ethanol have been studied using experiments and calculations. The results indicate that for DH and DA, the hydrogen and oxygen atoms on the phenolic hydroxyl group, the hydrogen atoms on the amino group, and even the hydrogen atom on the aromatic ring all can form hydrogen bonding with ethanol. However, the hydrogen atoms on $-\mathrm{NH}_{3}{ }^{+},-\mathrm{NH}_{2}$ and the phenolic hydroxyl groups show different ability in the formation of hydrogen bonding in the two mixtures. The present results are hopeful to be useful for understanding of the effect of ethanol on activity of dopamine systems, thus can provide theory support for exploring the mechanism and the treatment of ethanol addiction.

\section{Acknowledgments}

Financial support from the Science and Technology Development Program of Henan province of china (144300510034 and 142300410125), Foundation of Henan Educational Committee (15A150042) and the NSF for Distinguished Young Scholars of Shandong Province (JQ201303) is gratefully acknowledged.

\section{References}

[1] M. Melis, M. Diana, P. Enrico, M. Marinelli, M.S. Brodie, Alcohol 43 (2009) 531-539.

[2] L.C.Batista, R. D. S.Prediger, G.S. Morato, R.N. Takahashi, Psychopharmacology 181 (2005) 714-721.

[3] K.E. Bosse, T.A. Mathews, Neurosci. Let. 489 (2011) 172-176.

[4] K. Björk, V. Tronci, A. Thorsell, G. Tanda, N. Hirth, M. Heilig, A.C. Hansson, W. H. 
Sommer. Psychopharmacology 230 (2013) 439-449.

[5] K.A.Young, K.L. Gobrogge, Z.X. Wang, Neurosci. Biobehav. R. 35 (2011) 498-515.

[6] A.K. George, S. Balarama Kaimal, C.S. Paulose, Mol. Cell. Biochem. 304 (2007) 181-188.

[7] W.M. Doyon, A.M.Thomas, A. Ostroumov, Y. Dong, J.A. Dani, Biochem. Pharmacol. 86 (2013) 1181-1193.

[8] H.J. Yim, T. Schallert, P.K. Randall, P.M. Bungay, R.A. Gonzales, J. Neurochem. 68 (1997) $1527-1533$.

[9] N.G. Bacopoulos, I. Bize, J. Levine, L.S. Van Orden III, Psychopharmacology 60 (1979) 195-201.

[10] H. Trantham-Davidson, L.J. Chandler, Alcohol 49 (2015) 773-779.

[11] M. J. Frisch, G. W. Trucks, H. B. Schlegel, G. E. Scuseria, M. A. Robb, J. R. Cheeseman, G. Scalmani, V. Barone, B. Mennucci, G. A. Petersson, H. Nakatsuji, M. Caricato, X. Li, H. P. Hratchian, A. F. Izmaylov, J. Bloino, G. Zheng, J. L. Sonnenberg, M. Hada, M. Ehara, K. Toyota, R. Fukuda, J. Hasegawa, M. Ishida, T. Nakajima, Y. Honda, O. Kitao, H. Nakai, T. Vreven, J. A. Montgomery, Jr., J. E. Peralta, F. Ogliaro, M. Bearpark, J. J. Heyd, E. Brothers, K. N. Kudin, V. N. Staroverov, R. Kobayashi, J. Normand, K. Raghavachari, A. Rendell, J. C. Burant, S. S. Iyengar, J. Tomasi, M. Cossi, N. Rega, J. M. Millam, M. Klene, J. E. Knox, J. B. Cross, V. Bakken, C. Adamo, J. Jaramillo, R. Gomperts, R. E. Stratmann, O. Yazyev, A. J. Austin, R. Cammi, C. Pomelli, J. W. Ochterski, R. L. Martin, K. Morokuma, V. G. Zakrzewski, G. A. Voth, P. Salvador, J. J. Dannenberg, S. Dapprich, A. D. Daniels, O. Farkas, J. B. Foresman, J. V. Ortiz, J. Cioslowski, D. J. Fox, Gaussian 09, Revision D.01; Gaussian, Inc.: Wallingford, CT, (2009).

[12] S.F. Boys, F. Bernardi, Mol. Phys. 19 (1970) 553-566.

[13] F. Biegler-König, AIM2000, University of Applied Sciences, Bielefeld, Germany (2000).

[14] M.D. Hawley, S.V. Tatawawadi, S. Piekarski, R.N. Adarns, J. Am. Chem. Soc. 89 (1967) $447-450$.

[15] H.Y. Hou, F. Vacandio, M.L.D. Vona, P. Knauth, J.Appl. Polym. Sci. 129 (2013) 1151-1156.

[16] Y.F. Zhao, Y.Q. Gao, D.P. Zhan, H. Liu, Q. Zhao, Y. Kou, Y.H. Shao, M.X. Li, Q.K. Zhuang, Z.W. Zhu, Talanta 66 (2005) 51-57. 
[17] C.P. Zhai, D. Li, L.N. Li, F. Sun, H.T. Ma, X.J. Liu. Spectrochim. Acta Part A 145 (2015) 500-504.

[18] C.P. Zhai, H.T. Ma, F. Sun, L.N. Li, A.X. Song, J. Mol. Liq. 215 ( 2016) 481-485.

[19] R.N. Singh, V. Baboo, P. Rawat, A. Kumar, D. Verma. Spectrochim. Acta Part A 94 (2012) 288-301.

[20] K. Srivastava, M.R. Shimpi, A. Srivastava, P. Tandon, K. Sinha, S.P. Velaga, RSC Adv. 6 (2016) 10024.

[21] H.K. Wang, Z.G. Huang, T.T. Shen, L.F. Guo, J. Mol. Model. 18 (2012) 3113-3123.

[22] Z.G. Huang, Y.M. Dai, L.Yu, Struct. Chem. 21 (2010) 863-872.

[23] M. Małecka, Struct. Chem. 21 (2010) 175-184.

[24] B.A. Shainyan, N.N. Chipanina, T.N. Aksamentova, L.P. Oznobikhina, G.N. Rosentsveig, I.B. Rosentsveig, Tetrahedron 66 (2010) 8551-8556.

[25] E. Khan, A. Shukla, A. Srivastava, S. Shweta, P. Tandon, New J. Chem. 39 (2015) 9800-9812.

[26] U. Koch, P. Popelier, J. Phys. Chem. A 99 (1995) 9747-9754.

[27] M. Zahedi-Tabrizi, F. Ektefa. Monatsh. Chem. 146 (2015) 1837-1843.

[28] I. Rozas, I. Alkorta, J. Elguero, J. Am. Chem. Soc. 122 (2000) 11154-11161.

[29] Z.G. Huang, L.F. Guo, T.T. Shen, L.L. Ma, X.Q. Niu. Phys. Chem. Chem. Phys. 14 (2012) 8083-8089. 
Fig. 1. Cyclic voltammograms of DH in ethanol. The concentration of DH (from top to bottom, $\mathrm{mmol} \mathrm{L}^{-1}$ ) is: $0.125,0.250,0.500,1.00,2.00,4.00,8.00$, and 16.0.

Fig. 2. Molecular graphs of $\mathrm{DH}^{+}$species and ethanol molecule in gas phase.

Fig. 3. Optimized geometry of interaction between the $\mathrm{DH}^{+}$species and ethanol molecule in gas phase.

Fig. 4. Molecular graphs of DA and ethanol molecule in gas phase.

Fig. 5. Optimized geometry of interactions between DA and ethanol molecules in gas phase. 


\section{Tables}

Table 1. Lengths and angles of hydrogen bonding and interaction energies in $\mathrm{DH}^{+}$-ethanol complexes.

\begin{tabular}{|c|c|c|c|c|c|c|c|c|}
\hline \multirow[t]{2}{*}{ complex } & \multirow[t]{2}{*}{ bond length } & \multicolumn{2}{|c|}{$(\AA)$} & \multirow[t]{2}{*}{ bond angle } & \multicolumn{2}{|c|}{ degree } & \multicolumn{2}{|c|}{$\Delta E(\mathrm{kcal} / \mathrm{mol})$} \\
\hline & & in gas & in ethanol & & in gas & in ethanol & in gas & in ethanol \\
\hline \multirow[t]{2}{*}{ a1 } & $\mathrm{H} 11 \cdots \mathrm{O} 30$ & 1.697 & 1.763 & $\mathrm{O} 10-\mathrm{H} 11 \cdots \mathrm{O} 30$ & 165.0 & 162.4 & -9.61 & -4.33 \\
\hline & $\mathrm{H} 31 \cdots \mathrm{O} 12$ & 2.553 & 2.600 & $\mathrm{O} 30-\mathrm{H} 31 \cdots \mathrm{O} 12$ & 103.2 & 102.9 & & \\
\hline \multirow[t]{2}{*}{$\mathrm{a} 2$} & $\mathrm{H} 31 \cdots \mathrm{O} 10$ & 2.202 & 1.920 & $\mathrm{O} 30-\mathrm{H} 31 \cdots \mathrm{O} 10$ & 136.4 & 166.7 & -5.17 & -3.10 \\
\hline & $\mathrm{H} 9 \cdots \mathrm{O} 30$ & 2.255 & & C4-H9...O30 & 141.4 & & & \\
\hline a3 & $\mathrm{H} 11 \cdots \mathrm{O} 30$ & 1.722 & 1.783 & $\mathrm{O} 10-\mathrm{H} 11 \cdots \mathrm{O} 30$ & 162.9 & 158.7 & -8.87 & -4.36 \\
\hline a4 & $\mathrm{H} 13 \cdots \mathrm{O} 30$ & 1.742 & 1.707 & $\mathrm{O} 12-\mathrm{H} 13 \cdots \mathrm{O} 30$ & 173.1 & 174.3 & -13.82 & -6.64 \\
\hline a5 & $\mathrm{H} 22 \cdots \mathrm{O} 30$ & 1.653 & 1.744 & $\mathrm{~N} 20-\mathrm{H} 22 \cdots \mathrm{O} 30$ & 178.4 & 171.7 & -21.59 & -6.19 \\
\hline a6 & $\mathrm{H} 32 \cdots \mathrm{O} 30$ & 1.665 & 1.763 & $\mathrm{~N} 20-\mathrm{H} 32 \cdots \mathrm{O} 30$ & 178.7 & 177.5 & -21.77 & -6.98 \\
\hline a7 & $\mathrm{H} 32 \cdots \mathrm{O} 30$ & 1.661 & 1.748 & $\mathrm{~N} 20-\mathrm{H} 32 \cdots \mathrm{O} 30$ & 177.8 & 179.3 & -22.30 & -6.70 \\
\hline
\end{tabular}


Table 2. Lengths and angles of hydrogen bonding and interaction energies in DA-ethanol complexes.

\begin{tabular}{|c|c|c|c|c|c|c|c|c|}
\hline \multirow[t]{2}{*}{ complex } & \multirow[t]{2}{*}{ bond length } & \multicolumn{2}{|r|}{$(\AA)$} & \multirow[t]{2}{*}{ bond angle } & \multicolumn{2}{|c|}{ degree } & \multicolumn{2}{|c|}{$\Delta E(\mathrm{kcal} / \mathrm{mol})$} \\
\hline & & in gas & in ethanol & & in gas & in ethanol & in gas & in ethanol \\
\hline \multirow[t]{2}{*}{ b1 } & $\mathrm{H} 11 \cdots \mathrm{O} 28$ & 1.805 & 1.783 & 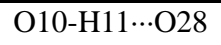 & 162.1 & 168.2 & -7.85 & -4.44 \\
\hline & $\mathrm{H} 29 \cdots \mathrm{O} 12$ & 2.005 & 2.123 & $\mathrm{O} 28-\mathrm{H} 29 \cdots \mathrm{O} 12$ & 135.4 & 130.3 & & \\
\hline \multirow[t]{2}{*}{ b2 } & $\mathrm{H} 29 \cdots \mathrm{O} 10$ & 1.994 & 1.978 & $\mathrm{O} 28-\mathrm{H} 29 \cdots \mathrm{O} 10$ & 154.8 & 162.8 & -5.79 & -3.76 \\
\hline & $\mathrm{H} 9 \cdots \mathrm{O} 28$ & 2.576 & & $\mathrm{C} 4-\mathrm{H} 9 \cdots \mathrm{O} 28$ & 126.3 & & & \\
\hline b3 & $\mathrm{H} 29 \cdots \mathrm{O} 12$ & 2.196 & 1.994 & $\mathrm{O} 28-\mathrm{H} 29 \cdots \mathrm{O} 12$ & 154.9 & 165.0 & -5.13 & -3.64 \\
\hline b4 & $\mathrm{H} 13 \cdots \mathrm{O} 28$ & 1.786 & 1.711 & $\mathrm{O} 12-\mathrm{H} 13 \cdots \mathrm{O} 28$ & 173.1 & 174.1 & -10.51 & -6.38 \\
\hline b5 & $\mathrm{H} 22 \cdots \mathrm{O} 28$ & 2.150 & 2.169 & $\mathrm{~N} 20-\mathrm{H} 22 \cdots \mathrm{O} 28$ & 159.5 & 166.6 & -5.19 & -2.32 \\
\hline b6 & $\mathrm{H} 21 \cdots \mathrm{O} 28$ & 2.098 & 2.111 & $\mathrm{~N} 20-\mathrm{H} 21 \cdots \mathrm{O} 28$ & 169.0 & 165.9 & -4.38 & -2.35 \\
\hline b7 & $\mathrm{H} 21 \cdots \mathrm{O} 28$ & 2.221 & 2.256 & $\mathrm{~N} 20-\mathrm{H} 21 \cdots \mathrm{O} 28$ & 144.5 & 148.9 & -4.85 & -2.33 \\
\hline
\end{tabular}


Table 3. Topological parameters of hydrogen bonding in $\mathrm{DH}^{+}$-ethanol complexes in gas phase.

\begin{tabular}{|c|c|c|c|c|c|c|}
\hline complex & hydrogen bonding & $\rho$ & $\nabla^{2} \rho$ & $V$ & $G$ & $H$ \\
\hline \multirow[t]{2}{*}{ a1 } & 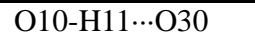 & 0.044309 & 0.139141 & -0.041871 & 0.038328 & -0.003543 \\
\hline & $\mathrm{O} 30-\mathrm{H} 31 \cdots \mathrm{O} 12$ & 0.009334 & 0.038582 & -0.007105 & 0.008375 & 0.001270 \\
\hline \multirow[t]{2}{*}{$\mathrm{a} 2$} & $\mathrm{O} 30-\mathrm{H} 31 \cdots \mathrm{O} 10$ & 0.014389 & 0.054265 & -0.010088 & 0.011827 & 0.001739 \\
\hline & $\mathrm{C} 4-\mathrm{H} 9 \ldots \mathrm{O} 30$ & 0.015369 & 0.048929 & -0.009400 & 0.010816 & 0.001416 \\
\hline a3 & 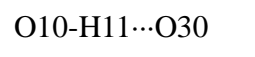 & 0.041479 & 0.133741 & -0.038216 & 0.035826 & -0.002390 \\
\hline a4 & $\mathrm{O} 12-\mathrm{H} 13 \cdots \mathrm{O} 30$ & 0.040060 & 0.131084 & -0.036576 & 0.034674 & -0.001902 \\
\hline a5 & $\mathrm{N} 20-\mathrm{H} 22 \cdots \mathrm{O} 30$ & 0.049963 & 0.145503 & -0.048693 & 0.042534 & -0.006159 \\
\hline a6 & $\mathrm{N} 20-\mathrm{H} 32 \cdots \mathrm{O} 30$ & 0.048447 & 0.144220 & -0.046708 & 0.041381 & -0.005327 \\
\hline a7 & $\mathrm{N} 20-\mathrm{H} 32 \cdots \mathrm{O} 30$ & 0.049024 & 0.144810 & -0.047435 & 0.041819 & -0.005616 \\
\hline
\end{tabular}


Table 4. Topological parameters of hydrogen bonding in $\mathrm{DH}^{+}$-ethanol complexes in ethanol.

\begin{tabular}{|c|c|c|c|c|c|c|}
\hline complex & hydrogen bonding & $\rho$ & $\nabla^{2} \rho$ & $V$ & $G$ & $H$ \\
\hline a1 & O10-H11‥O30 & 0.038133 & 0.124430 & -0.033780 & 0.032443 & -0.001337 \\
\hline $\mathrm{a} 2$ & $\mathrm{O} 30-\mathrm{H} 31 \cdots \mathrm{O} 10$ & 0.025541 & 0.096595 & -0.019969 & 0.022059 & 0.002090 \\
\hline a3 & $\mathrm{O} 10-\mathrm{H} 11 \cdots \mathrm{O} 30$ & 0.036302 & 0.121061 & -0.031631 & 0.030948 & -0.000683 \\
\hline $\mathrm{a} 4$ & $\mathrm{O} 12-\mathrm{H} 13 \cdots \mathrm{O} 30$ & 0.043657 & 0.135564 & -0.040781 & 0.037336 & -0.003445 \\
\hline a5 & $\mathrm{N} 20-\mathrm{H} 22 \cdots \mathrm{O} 30$ & 0.040750 & 0.127995 & -0.036218 & 0.034108 & -0.002110 \\
\hline a6 & $\mathrm{N} 20-\mathrm{H} 32 \cdots \mathrm{O} 30$ & 0.039143 & 0.122645 & -0.033893 & 0.032277 & -0.001616 \\
\hline a7 & $\mathrm{N} 20-\mathrm{H} 32 \cdots \mathrm{O} 30$ & 0.039201 & 0.129675 & -0.034999 & 0.033709 & -0.001290 \\
\hline
\end{tabular}


Table 5. Topological parameters of hydrogen bonding in DA-ethanol complexes in gas phase.

\begin{tabular}{|c|c|c|c|c|c|c|}
\hline complex & hydrogen bonding & $\rho$ & $\nabla^{2} \rho$ & V & $G$ & $H$ \\
\hline \multirow[t]{2}{*}{$\mathrm{b} 1$} & 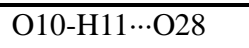 & 0.035940 & 0.115689 & -0.030713 & 0.029818 & -0.000895 \\
\hline & $\mathrm{O} 28-\mathrm{H} 29 \cdots \mathrm{O} 12$ & 0.022869 & 0.088387 & -0.018004 & 0.020050 & 0.002046 \\
\hline \multirow[t]{2}{*}{ b2 } & $\mathrm{O} 28-\mathrm{H} 29 \cdots \mathrm{O} 10$ & 0.021620 & 0.084289 & -0.016311 & 0.018692 & 0.002381 \\
\hline & $\mathrm{C} 4-\mathrm{H} 9 \ldots \mathrm{O} 28$ & 0.008628 & 0.027338 & -0.005233 & 0.006034 & 0.000801 \\
\hline b3 & $\mathrm{O} 28-\mathrm{H} 29 \cdots \mathrm{O} 12$ & 0.014743 & 0.051772 & -0.009863 & 0.011403 & 0.001540 \\
\hline b4 & $\mathrm{O} 12-\mathrm{H} 13 \cdots \mathrm{O} 28$ & 0.035390 & 0.123440 & -0.031114 & 0.030987 & -0.000127 \\
\hline b5 & $\mathrm{N} 20-\mathrm{H} 22 \cdots \mathrm{O} 28$ & 0.016879 & 0.059183 & -0.011074 & 0.012935 & 0.001861 \\
\hline b6 & $\mathrm{N} 20-\mathrm{H} 21 \cdots \mathrm{O} 28$ & 0.017884 & 0.066961 & -0.012168 & 0.014454 & 0.002286 \\
\hline b7 & $\mathrm{N} 20-\mathrm{H} 21 \cdots \mathrm{O} 28$ & 0.014959 & 0.051688 & -0.009767 & 0.011345 & 0.001578 \\
\hline
\end{tabular}


Table 6. Topological parameters of hydrogen bonding in DA-ethanol complexes in ethanol.

\begin{tabular}{|c|c|c|c|c|c|c|}
\hline complex & hydrogen bonding & $\rho$ & $\nabla^{2} \rho$ & $V$ & $G$ & $H$ \\
\hline \multirow[t]{2}{*}{$\overline{\mathrm{b} 1}$} & 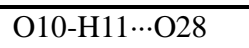 & 0.037415 & 0.118553 & -0.032364 & 0.031001 & -0.001363 \\
\hline & $\mathrm{O} 28-\mathrm{H} 29 \cdots \mathrm{O} 12$ & 0.018351 & 0.067822 & -0.013600 & 0.015278 & 0.001678 \\
\hline b2 & $\mathrm{O} 28-\mathrm{H} 29 \cdots \mathrm{O} 10$ & 0.023021 & 0.084239 & -0.017188 & 0.019124 & 0.001936 \\
\hline b3 & $\mathrm{O} 28-\mathrm{H} 29 \cdots \mathrm{O} 12$ & 0.022097 & 0.081185 & -0.016245 & 0.018271 & 0.002026 \\
\hline b4 & $\mathrm{O} 12-\mathrm{H} 13 \cdots \mathrm{O} 28$ & 0.043260 & 0.135022 & -0.040280 & 0.037018 & -0.003262 \\
\hline b5 & $\mathrm{N} 20-\mathrm{H} 22 \cdots \mathrm{O} 28$ & 0.016855 & 0.055480 & -0.010825 & 0.012347 & 0.001522 \\
\hline b6 & $\mathrm{N} 20-\mathrm{H} 21 \cdots \mathrm{O} 28$ & 0.017809 & 0.064839 & -0.011967 & 0.014088 & 0.002121 \\
\hline b7 & $\mathrm{N} 20-\mathrm{H} 21 \cdots \mathrm{O} 28$ & 0.014426 & 0.046797 & -0.009180 & 0.010440 & 0.001260 \\
\hline
\end{tabular}


Figures

Figure 1

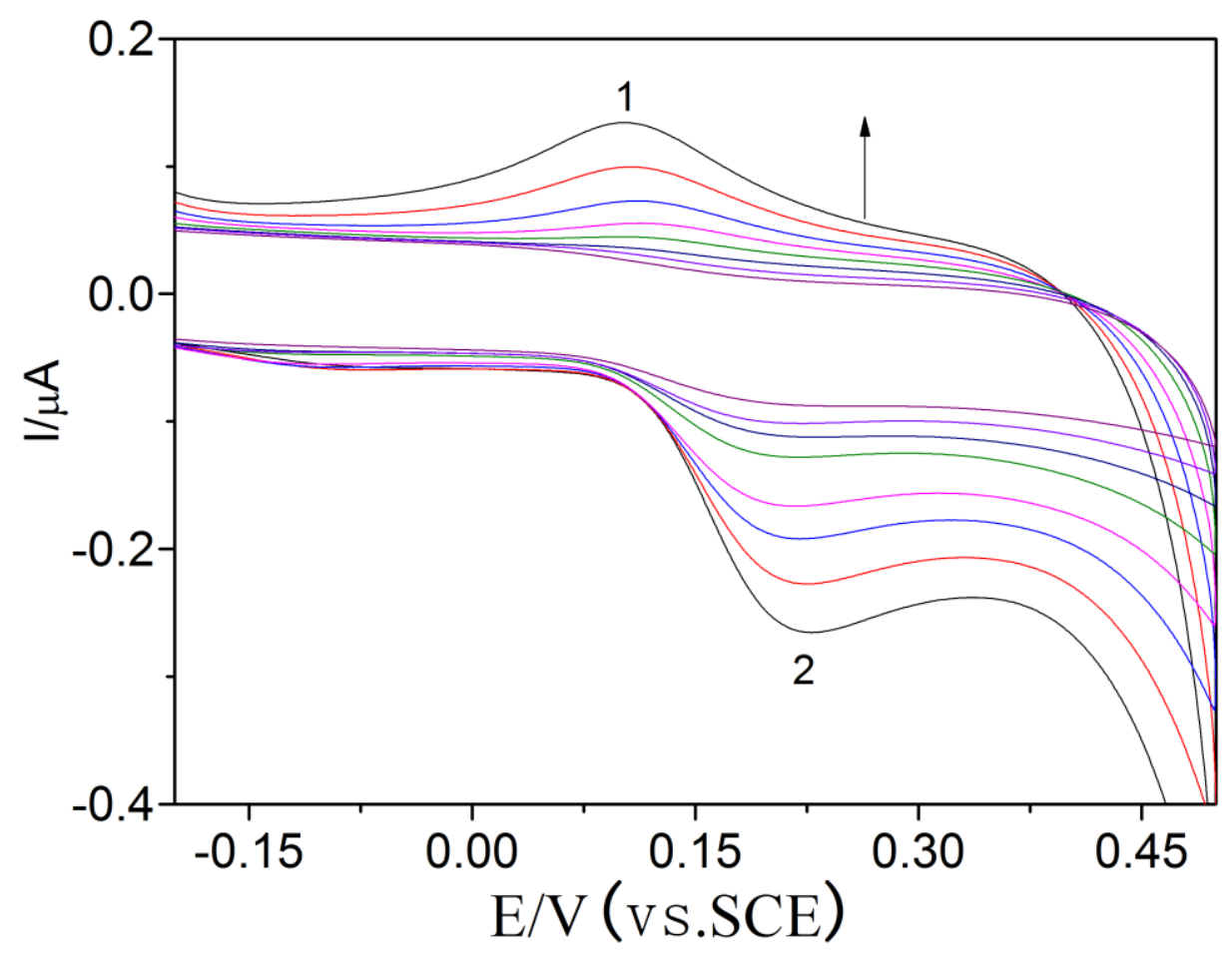


Figure 2

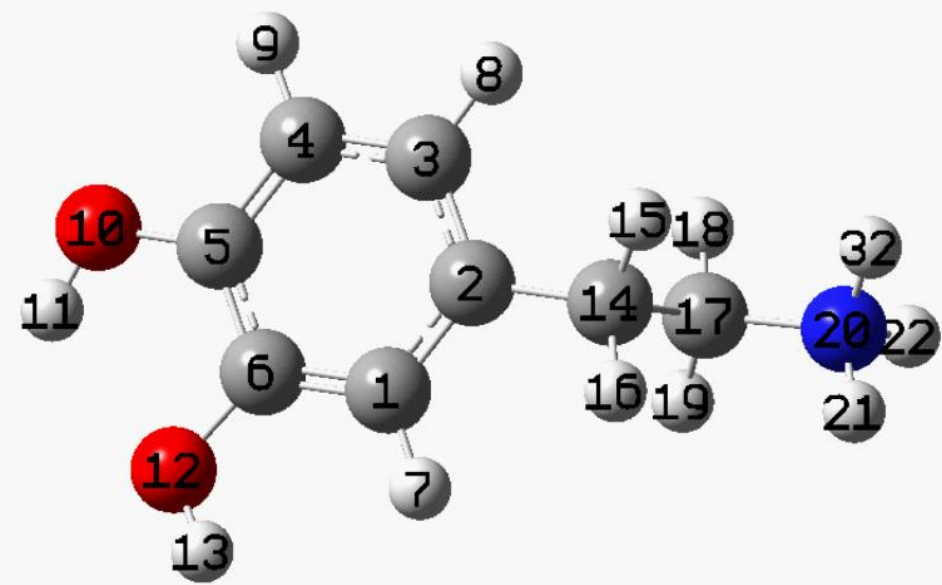

$\mathrm{DH}^{+}$

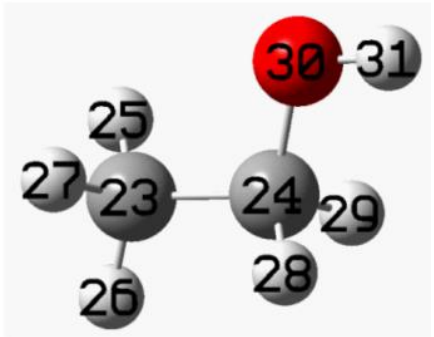

ethanol 
Figure 3
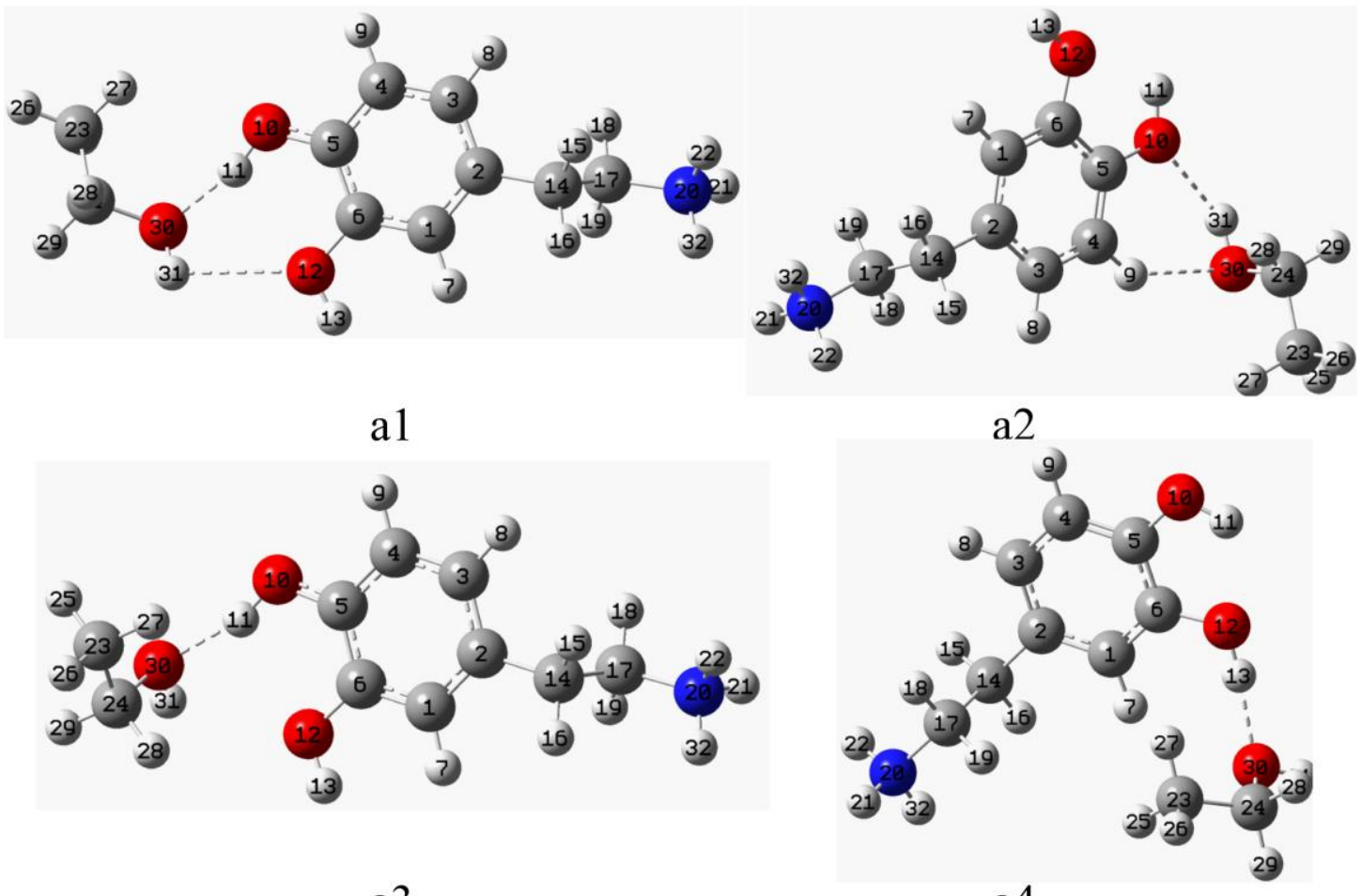

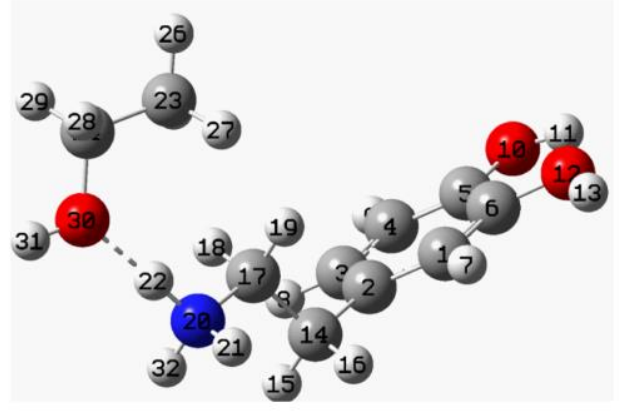

a5
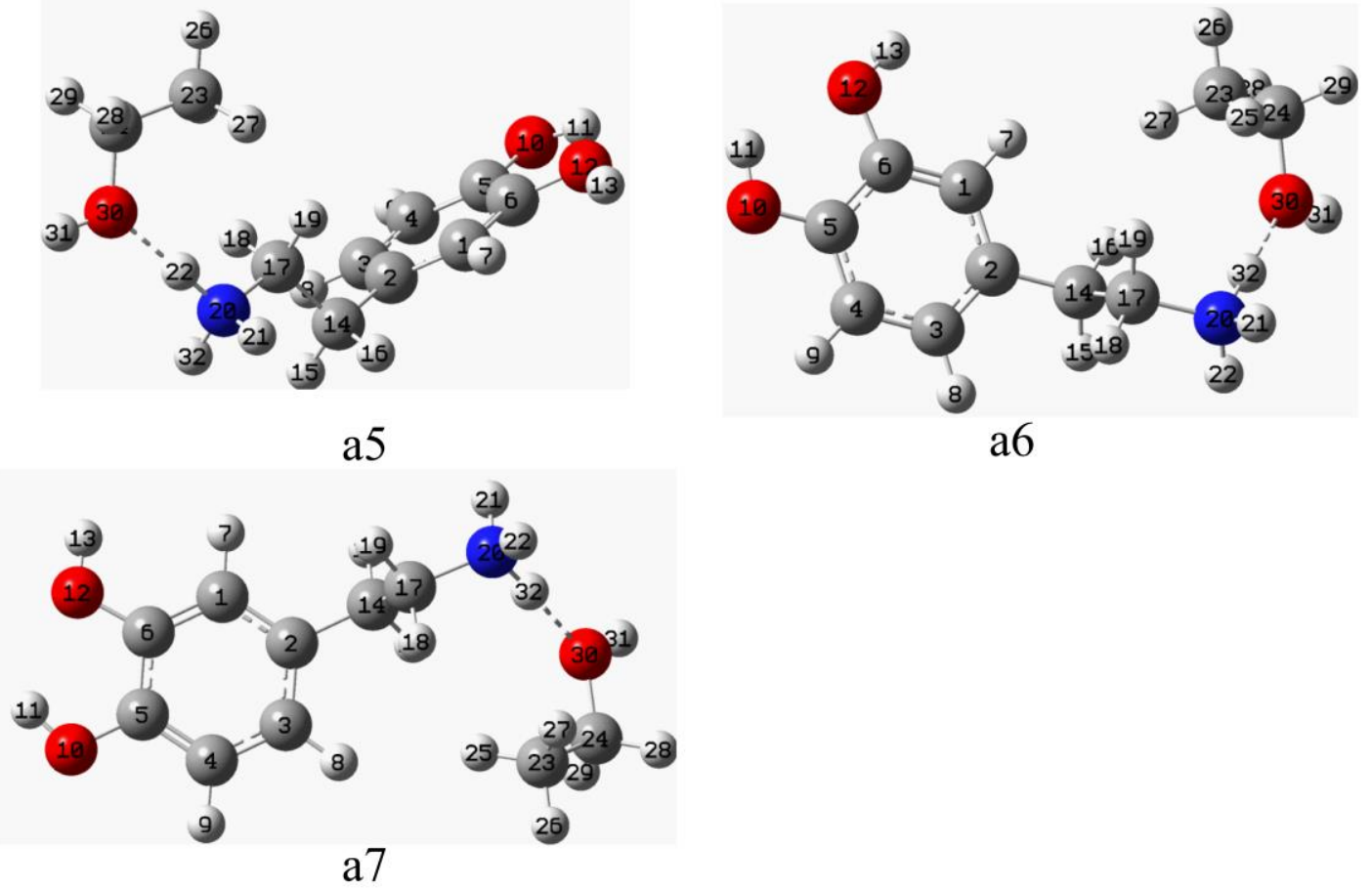
Figure 4

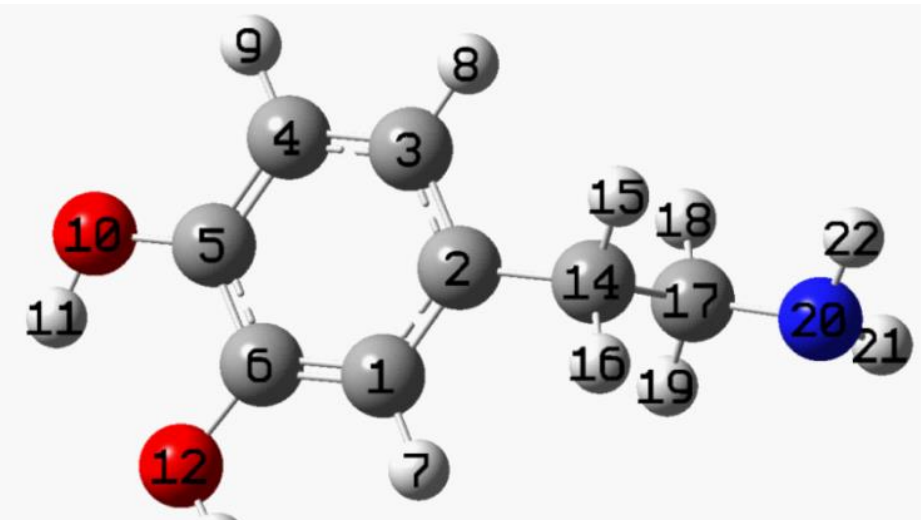

13

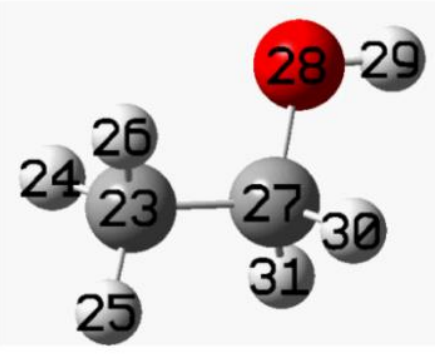

ethanol 
Figure 5

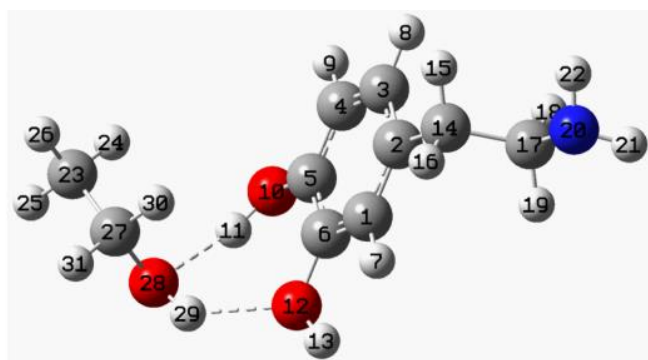

b1

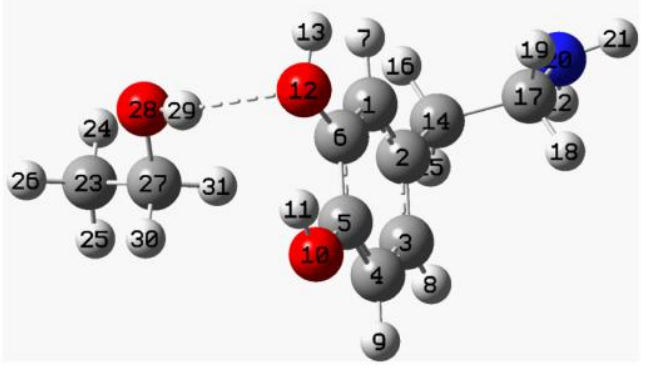

b3

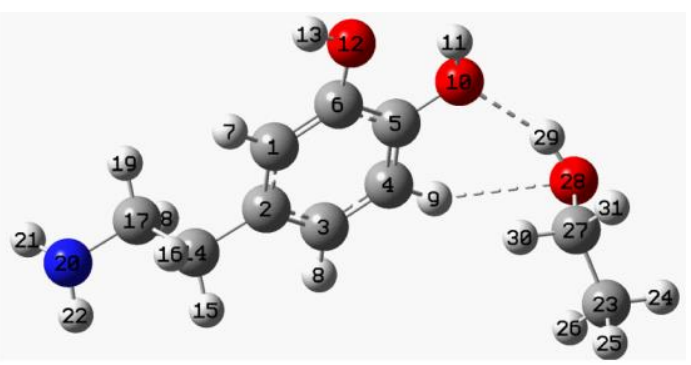

b2

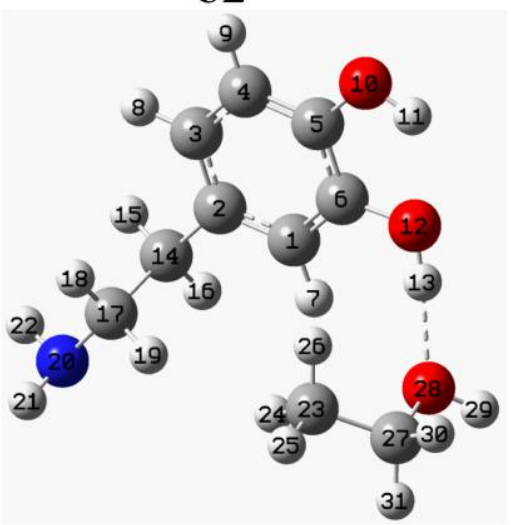

b4
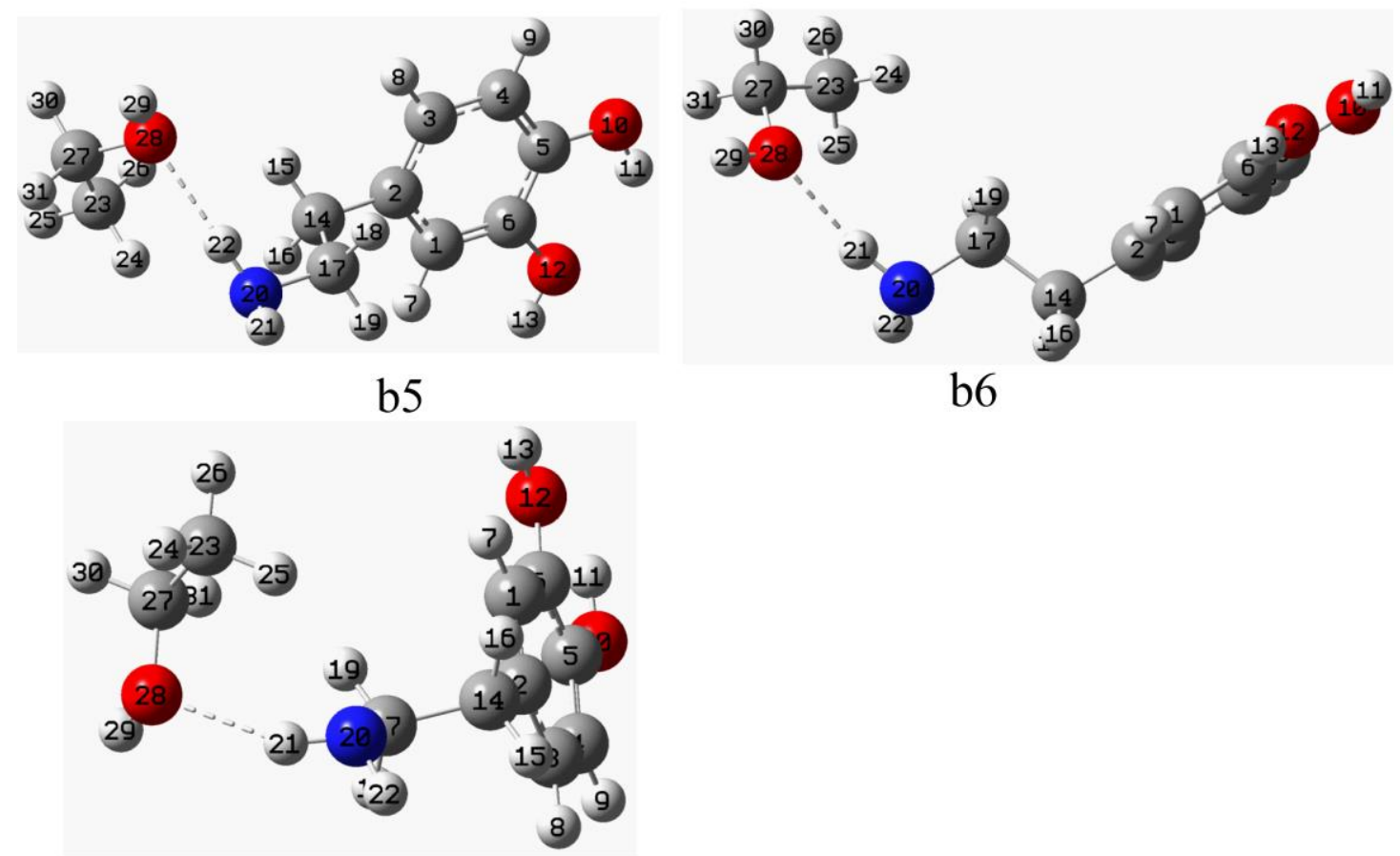

b7 


\section{Graphical Abstract}
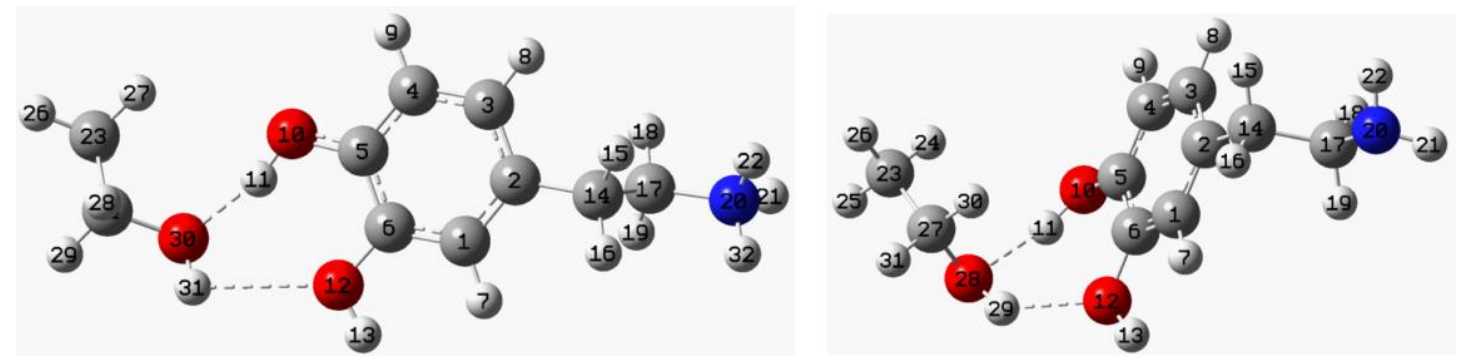